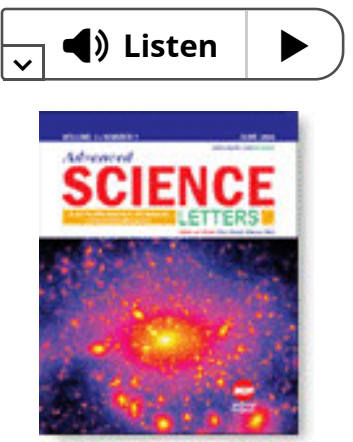

\title{
Impact of the Government Service Tax (GST) on the Malaysian Takaful Industry: Issues and Challenges
}

Buy Article:

$\$ 105.00+$ tax

(Refund Policy)

ADD TO CART

BUY NOW

Authors: Salleh, Marhanum Che Mohd; Yussof, Sheila Ainon; Abdullah, Nurdianawati Irwani

Source: Advanced Science Letters, Volume 24, Number 5, May 2018, pp. 3178-3183(6)

Publisher: American Scientific Publishers

DOI: https://doi.org/10.1166/asl.2018.11339

References

Citations

Supplementary Data

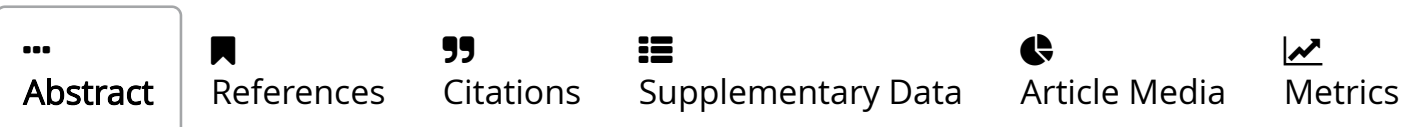

Malaysia is reputed to be a leader in the Takaful industry within the ASEAN region commanding a market share that exceeds 70 percent of gross Takaful contribution. The industry however is not exempted from the recent implementation of the Malaysian Goods and Services Tax (GST) in April 2015. This study seeks to examine the specific Shari'ah issues and challenges that may be triggered off by GST application on its operations. An inductive analysis will be undertaken on the relevant sources that justify GST implementation in Takaful, mainly guidelines provided by Customs Department, and also arguments from scholars on the likely contravention of Shari'ah principles with the application of GST. This research will be significant as it will make an in-depth analysis of GST application whilst identifying the areas of non-compliances with Shari'ah. Recommendations will be made for regulators to overcome the Shari'ah issues and challenges that have emerged from its implementation.

Keywords: Challenges; Government Service Tax; Shari'ah Issues; Takaful Industry

Document Type: Research Article 
Affiliations: Department of Finance, Kulliyyah of Economics and Management Sciences, International Islamic University Malaysia, Malaysia

Publication date: May 1, 2018

More about this publication? 